\title{
Impairment of Spermatogonial Development and Spermiation after Testosterone-Induced Gonadotropin Suppression in Adult Monkeys (Macaca fascicularis)*
}

\author{
LIZA O’DONNELL, ANITA NARULA, GEORGIA BALOURDOS, YI-QUN GU, \\ NIGEL G. WREFORD, DAVID M. ROBERTSON, WILLIAM J. BREMNER, AND \\ ROBERT I. MCLACHLAN \\ Prince Henry's Institute of Medical Research (L.O., G.B., D.M.R., R.M.), Clayton, Victoria 3168, \\ Australia; Population Center for Research in Reproduction (A.N., Y.-Q.G., W.J.B.), Department of \\ Medicine, University of Washington, Seattle, Washington 98195; and Department of Anatomy and Cell \\ Biology (N.G.W.), Monash University, Clayton, Victoria 3168, Australia
}

\begin{abstract}
Human male hormonal contraceptive regimens do not consistently induce azoospermia, and the basis of this variable response is unclear. This study used nine adult macaque monkeys (Macaca fascicularis) given testosterone (T) implants for 20 weeks to study changes in germ cell populations in relation to sperm output. Germ cell numbers were determined using the optical disector stereological method. Four animals achieved consistent azoospermia (azoo group), whereas five animals did not (nonazoo group). T-induced gonadotropin suppression in all animals decreased A pale (Ap) spermatogonia to $45 \%$ of baseline within 2 weeks, leading to decreased B spermatogonia (32-38\%) and later germ cells $(20-30 \%)$ after 14 and 20 weeks. Though the reduction in later germ cell types could be primarily attributed to the loss
\end{abstract}

of spermatogonia, the data suggested that some cells were lost during the spermatocyte and spermatid phase of development. B spermatogonial number was more markedly suppressed in azoospermic animals, compared with the nonazoo group, as was the conversion ratio between Ap and B spermatogonia. Abnormal retention of elongated spermatids (failed spermiation) was also prominent in some animals after long-term $\mathrm{T}$ administration. We conclude that: 1) the variable suppression of sperm output is attributed to the degree of inhibition of germ cell development from type B spermatogonia onwards, and this is related to the degree of FSH suppression; and 2) inhibition of Ap and B spermatogonial development and of spermiation are the major defects caused by long-term $\mathrm{T}$ administration to monkeys. (J Clin Endocrinol Metab 86: 1814-1822, 2001)
$\mathrm{T}$ HE ADMINISTRATION OF exogenous testosterone (T), either alone or in combination with a progestin, reduces the secretion of the pituitary gonadotropins, LH and $\mathrm{FSH}$, and thereby sperm production, and is a promising approach to male contraception (1). A feature of many such contraceptive formulations is the variable induction of azoospermia, ranging from $70-95 \%$, depending on the regimen and ethnic group under study (1-4). Though sperm counts of less than 3 million per $\mathrm{mL}$ may provide adequate contraception (4), there is a general consensus that the reliable induction of azoospermia is important to ensure contraceptive efficacy and the widespread acceptance of male hormonal contraception. An understanding of the biological basis for the variable response is essential to this goal.

Although many studies have investigated the effects of hormone suppression on spermatogenesis in the rat (5-7),

Received October 4, 2000. Revision received December 4, 2000. Accepted December 19, 2000

Address all correspondence and requests for reprints to: Liza O'Donnell, Ph.D., Prince Henry's Institute of Medical Research, P.O. Box 5152, Clayton, Victoria 3168, Australia. E-mail: liza.odonnell@med. monash.edu.au.

* Supported in part by Contraceptive Research and Development Program (CONRAD) Grants CSA-98-231 and CSA-98-232 and the Mellon Foundation. L.O. was supported by a Wellcome Trust Research Training Fellowship in Reproductive Biology (No. 050387). D.M.R. and R.I.M. were supported by Program Grant 983212 from the National Health and Medical Research Council of Australia. N.G.W. was supported by Australian Research Council Grant 9927208. fewer studies have investigated the effects of FSH and LH/ testicular T suppression on germ cell development in monkeys and man. In monkeys rendered gonadotropin-deficient by hypophysectomy or GnRH antagonist treatment, spermatogonia are the most sensitive germ cell type (8-11); however, which spermatogonial subtypes are regulated by hormones is controversial $(9,11-14)$. A recent study in men receiving weekly injections of $\mathrm{T}$ enanthate suggested that the inhibition of spermatogonial development was also the primary lesion in response to gonadotropin withdrawal and further suggested that the failure of sperm release may also be important (15). In accordance with this latter observation, our recent study in rats showed that spermiation failure contributes to the suppression of spermatogenesis after hormone withdrawal (16).

Potential T-based contraceptive regimens in monkeys and humans clearly inhibit various phases of germ cell development; however, the relationship between these changes and the extent of suppression of sperm output is unclear. Our recent results in monkeys given $\mathrm{T}$ implants indicated that animals who achieve stable azoospermia in response to 20 weeks of T administration have significantly lower levels of circulating FSH, compared with those animals who did not achieve consistent azoospermia, whereas no differences were seen in LH or T (serum or testicular) levels (17).

The purpose of this study is to describe the time course of the effects of exogenous $\mathrm{T}$ administration on germ cell development in macaque monkeys and to relate the degree of 
suppression of germ cell development to sperm output. The optical disector stereological technique was used for the unbiased determination of Sertoli cell and germ cell number in testicular biopsies taken before, during, and after $\mathrm{T}$ administration. The data show that reductions in type A pale (Ap) and $\mathrm{B}$ spermatogonia are the key lesions in spermatogenesis and that failure of spermiation is also important.

\section{Materials and Methods \\ Animals and study design}

Nine normal adult male crab-eating macaque monkeys, Macaca fascicularis (age, 5-12 yr; BW, 5-9 kg) were housed in the Regional Primate Research Center at the University of Washington, under defined environmental conditions. All procedures were performed in accordance with the Endocrine Society Guidelines for the Care and Use of Experimental Animals (18). All procedures were carried out under Ketamine (Fort Dodge, IA) $\mathrm{HCl}$ (10 mg/kg, im) anesthesia. Valium (1 mg/kg; im, Elkins-Sinn, Inc., Cherry Hill, NJ) was given, before Ketamine $\mathrm{HCl}$, to all monkeys, for the electroejaculation procedure.

The study involved a pretreatment (control) phase (4 weeks), treatment phase (20 weeks) terminating with the removal of the implants, and recovery phase (16 weeks). T was administered via sterilized sc SILASTIC implants $(5.5-\mathrm{cm}$ long; inside diameter, $0.33 \mathrm{~cm}$; outside diameter, $0.46 \mathrm{~cm}$ ) for 20 weeks. Two implants were inserted sc in the midscapular region of each animal.

\section{Testicular biopsies}

Open testicular biopsies were performed alternatively on the right and left testis, in aseptic conditions, under ketamine/xylazine anesthesia. All animals were biopsied 4 weeks before the treatment (control) and then at weeks 2,14, and 20 during the treatment and at 12 weeks post treatment. Approximately 300-500 mg tissue was taken per biopsy and was divided in half; half was frozen in liquid nitrogen for the measurement of testicular androgens (Narula et al., submitted). The other half was immersion-fixed in Bouin's fluid for approximately $5 \mathrm{~h}$, then stored in $70 \%$ ethanol. Biopsies were observed under a dissecting microscope and cut along a plane lying at right angles to the dominant tubule orientation, to maximize the number of circular tubule profiles.

\section{Testicular function and hormone data}

Body weights, testis volumes, and sperm counts were assessed every 2 weeks during control, treatment, and recovery periods. Testis volumes were measured using an orchidometer. Seminal fluid was collected after rectal probe electroejaculation, and total sperms counts (millions/ejaculate) were determined using a hemocytometer. Blood samples were collected from the femoral vein every 2 weeks during the study (Narula et al., submitted). Bioassays were used to measure the bioactivity of LH and FSH as detailed elsewhere (Narula et al., submitted). The detection limits of the assays were as follows: bioLH, $2.4 \mathrm{IU} / \mathrm{L}$; bioFSH, $0.08 \mathrm{IU} / \mathrm{L}$. Testicular T was measured using previously published methods (19) as detailed elsewhere (Narula et al., submitted).

For the purposes of the current study, hormone and semen data are included only from the time points where biopsies were taken to compare with stereological data. More detailed data on the endocrine parameters and sperm output every 2 weeks across the entire study are reported elsewhere (Narula et al., submitted).

\section{Tissue processing}

Bouin's fixed biopsy tissue was dehydrated through a series of ethanol and butanol steps, then processed and embedded in hydroxyethylmethacrylate resin (Technovit 7100, Kulzer and Co., Friedrichsdorf, Germany), according to the manufacturer's instructions. Thick $(25-\mu \mathrm{m})$ sections were cut using a Supercut microtome (Reichert Jung 2050, Nussloch, Germany) and stained with PAS (periodic acid-Schiff's reagent) and counterstained with hematoxylin.

\section{Cell identification and groupings}

Each seminiferous tubule was staged into one of the following stage groupings based on the cellular associations present in stages I-VI, VII, VIII-XI, and XII (see (Ref. 20), and the cells were counted in the following groups: Sertoli cells, type A dark (Ad) spermatogonia (present in all stages); type Ap spermatogonia (present in all stages); type B (B) spermatogonia (present in stages X-XII and I-VI); preleptotene + leptotene + zygotene (Pl-Z) primary spermatocytes (present in stages VII-XI); pachytene primary spermatocytes (PS) (present in all stages); round spermatids (rSt 1-7) (stages I-VII); elongating spermatids (eSt 8-12) in steps 8-12 (stages VIII-XII); and elongated spermatids (eSt 13-14) in steps 13-14 (stages I-VI).

Sertoli cells and germ cells, in $25-\mu \mathrm{m}$ thick PAS-stained methacrylate sections, were classified on the basis of their nuclear morphology, as previously described by Zhengwei (20), based on the criteria of Clermont $(21,22)$. Spermatogonia were subdivided into type Ad and type Ap spermatogonia, and type B spermatogonia as follows (see Fig. 1 for morphology of the various subclasses of spermatogonia):

Ad spermatogonia. Ad spermatogonia were variable in size, with a nucleus that showed darker staining, compared with Ap spermatogonia. The nuclei were rounded and often broadly applied to the basement membrane. Many nuclei contained a vacuole and/or lightly stained regions; and in most cases, the cytoplasm contained strong PAS-positive material (Fig. 1).

Ap spermatogonia. Ap spermatogonia had nuclei that were generally larger than Ad spermatogonia and were paler in color. The nuclei were almost always round and showed one or two clumps of chromatin associated with the nuclear membrane. The cytoplasm did not show PAS positive material (Fig. 1).
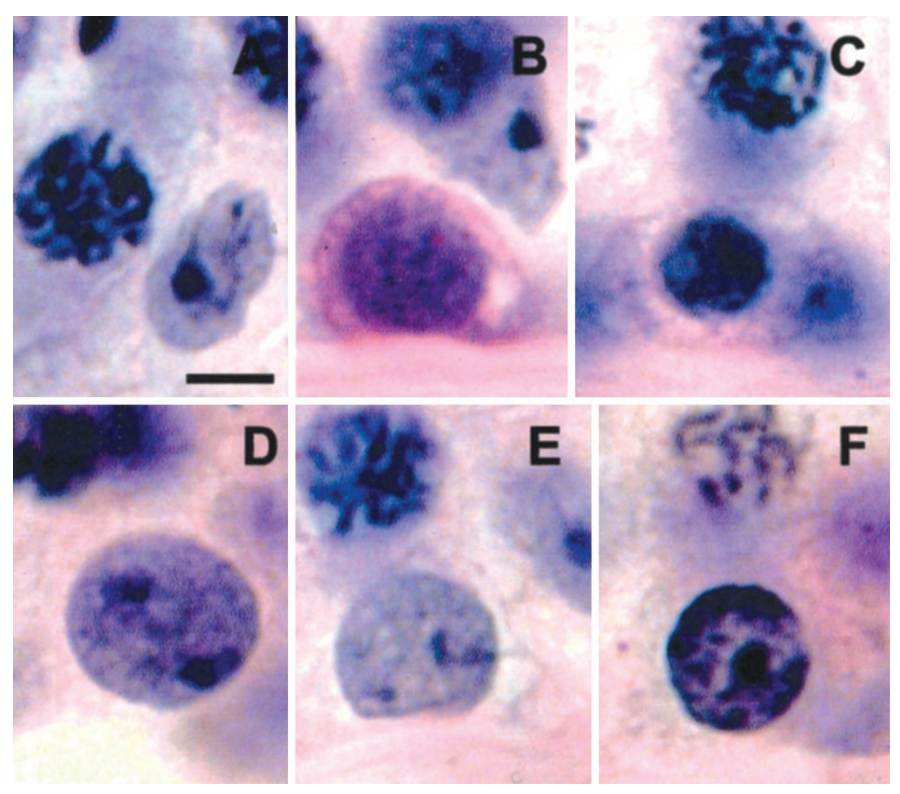

FIG. 1. Morphology of spermatogonia and Sertoli cell nuclei in 25$\mu \mathrm{m}$-thick sections of PAS stained, methacrylate-embedded monkey testicular biopsy material. A, Sertoli cell nucleus, showing characteristic irregular shape and central nucleolus. Bar, $5 \mu \mathrm{m}$. B, Ad spermatogonium, showing PAS-positive material in the cytoplasm. This morphology was seen in the majority of Ad spermatogonia. C, Ad spermatogonium with a darkly stained nucleus containing small vacuolated areas and a visible halo around the nucleus. D, Ap spermatogonium with a large, rounded, lightly stained nucleus containing two clumps of chromatin. E, Ap spermatogonium with a slightly lighter stained nucleus and two clumps of chromatin. F, B spermatogonium with a rounded, darkly-stained nucleus, showing the characteristic peripherally located chromatin and a central nucleolus. All micrographs were taken at the same magnification. 
B spermatogonia. B spermatogonia had nuclei that were rounded, darker in color, with peripherally located clumps of chromatin and a central nucleolus. The nuclei were situated further away from the basement membrane than Ad spermatogonia (Fig. 1).

Sertoli cells were clearly distinguishable from spermatogonia by their irregularly shaped pale-colored nucleus and the presence of a single prominent nucleolus (see Fig. 1). Criteria for classification of the later germ cell types have been described in detail in our previous study (20).

\section{Stereological analysis}

The optical disector method was used to determine the numbers of germ cells and Sertoli cells in each biopsy as previously described (20, 23). This method is an unbiased and efficient technique for estimating cell number, including nonspherical objects such as elongated spermatids, and assumes only that cell number equates to nuclear number. The $25-\mu \mathrm{m}$ methacrylate sections were optically sectioned by means of a high numerical aperture lens (100× objective lens, numerical aperture 1.4) on an Olympus Corp. (Tokyo, Japan) BX-50 microscope equipped with a microcater (Heideinhain D83301; Traunreut, Germany) attached to the microscope stage to monitor the depth scanned. The image was captured by a Pulinix TMC-6 video camera coupled to a Pentium personal computer using a Screen machine II fast multimedia video adapter (FAST, Hamburg, Germany). A software package, DH CASTGRID version 1.10 (Olympus Corp., Munich, Germany) was used to superimpose a set of unbiased counting frames on the video image. Fields to be counted were selected by a systematic uniform random sampling scheme, with the use of a motorized stage (Multicontrol 2000, ITK, Lahnau, Germany). In each field, 4 counting frames (area of each frame, $460.5 \mu \mathrm{m}^{2}$ ) were generated; cells that appeared infrequently (e.g. spermatogonia, preleptonene-tozygotene spermatocytes, and Sertoli cells) were counted in each of the 4 frames (total area, $1842 \mu \mathrm{m}^{2}$ ), whereas cells appearing more frequently (such as spermatids) were counted in one frame. In most cases, more than 100 cells were counted per cell grouping per biopsy. However, in some treated biopsies where spermatogenic suppression had occurred, approximately 40 cells were assessed in some germ cell categories.

During counting of germ cell and Sertoli cell nuclei, the position of a fixed point, at $-3 \mu \mathrm{m}$ in the z-axis, was determined in each field to assess the volume fraction of interstitium, seminiferous tubule, and stage of seminiferous tubule. The volume fraction of each stage grouping (I-VI, VII, VIII-XI, and XII) was calculated for each biopsy as an approximation of the relative frequency of each stage. In all control and T-treated testis biopsies counted, the relative stage frequencies obtained were compared with the published relative stage frequency, as determined by Fouquet and Dadoune in Macaca fascicularis (24) to ensure constant recognition of stages (and thus, accurate cell identification). Relative stage frequencies were also used to assess the within-biopsy and interanimal variation. The within-biopsy variation was shown to be $5-14 \%(n=9)$ for each stage grouping, and the interanimal variation was shown to be $9-19 \%$ $(n=9)$. In all treated biopsies, the relative stage frequencies for each stage grouping were similar to the published relative stage frequencies (24) and to the mean values obtained from nine control animals.

The numerical density (Nv) of each cell type was calculated as previously described (23). The Nv of each germ cell type was divided by the Nv of Sertoli cells to express the number of germ cells per Sertoli cell (N/SC). The use of the latter in evaluating the effects of hormones on spermatogenesis relies on the assumption that there are no changes in the number of Sertoli cells per testis. The validity of this assumption has been demonstrated previously in primates (Macaca fascicularis) receiving a GnRH antagonist (11). To compare germ cell types at the one time point, the percent control value was calculated by dividing N/SC of each germ cell type, during the treatment and recovery period, by the N/SC of the control biopsy. Conversion ratios (CR) were also used to assess differences in germ cell development between control and treated biopsies at each time point and were calculated by dividing the N/SC of one germ cell type by the N/SC of the preceding germ cell type in the cycle of spermatogenesis. The CR for each transition was then compared with the CR obtained for the control biopsies. CR were assessed in the 14- and 20-week testicular biopsies where stable spermatogenic suppression had been achieved. It should be noted that the CR were not adjusted for the relative stage duration; and therefore, these ratios cannot be used to assess the efficiency of spermatogenesis as in other studies (20). Rather, they were used to assess lesions to germ cell development by investigating significant differences between control and treated biopsies.

\section{Assessment of spermiation failure}

The release of mature step 14 spermatids via spermiation occurs at the end of stage VI/early stage VII; and thus, mature step 14 spermatid heads located in the basal portion of the epithelium from stage VII and beyond represent retained spermatids that do not undergo spermiation. The number of retained spermatids in stages VII-XII were counted, as per other germ cells, and expressed per Sertoli cell.

To compare the number of spermatids retained within the epithelium, with the number of normal spermatids available for spermiation, the number of retained spermatids in stages VII-XII and steps 13-14 spermatids in stages I-VI (N/SC) were corrected for the different duration of stages in which they are present, and were thus multiplied by the relative stage frequency for that stage grouping. The number of retained spermatids per Sertoli cell in stages VII-XII was then divided by the number of steps-13-14 spermatids (in stages I-VI) per Sertoli cell and multiplied by 100 , as an estimation of the percentage failing to spermiate. It should be noted that the comparison of retained spermatids to steps 13-14 spermatids is only an approximation of the percentage of spermatids failing to spermiate; because retained spermatids will undergo phagocytosis and disappear over the 136 -h period from stage VII to XII, and thus the number of retained spermatids counted will be an underestimation of the actual number retained. However, because of the severity of spermatogenic suppression in most animals, it was not possible to subdivide between these stages; and thus, all retained spermatid data were pooled.

Spermiation failure was only assessed in animals that had spermiogenic cells present in the biopsy during the T-administration period. Because three animals had severe spermatogenic arrest and no elongating or elongated spermatids present in the testis at either the 14- or 20-week treatment periods, these animals were excluded from this analysis.

\section{Statistics}

For comparison of one endpoint across the study period, data were log-transformed and tested for homogeneity of variance before repeated-measures one-way ANOVA. When a $P$ value of less than 0.05 was obtained by ANOVA, post hoc analysis was performed using Dunnett's test for differences compared with the control group, and NewmanKeuls post hoc comparison was performed for other differences between the various time points. When comparing between different germ cell populations, expressed as percent control, the loss of germ cells at different points in the spermatogenic cycle was associated with significant heterogeneity in variances; and thus, nonparametric analyses for correlated samples (Friedman ANOVA and Wilcoxen signed-rank test) were used. When comparing data between groups of animals achieving either consistent azoospermia (azoo group) and those that did not (nonazoo group), significant heterogeneity of variance was observed; and thus, the nonparametric Mann-Whitney $U$ test was used. Differences at the level of $P<0.05$ were considered significant. Data are expressed as mean $\pm \operatorname{sEM}(\mathrm{n}=9$ for all groups except the 14 -week treatment group, where $\mathrm{n}=8$ )

\section{Results}

Germ cell populations before, during, and after $T$ administration.

The effect of $\mathrm{T}$ administration on the number of each germ cell type (N/SC), in comparison with control values for all nine animals, is shown in Table 1 . After 2 weeks of $\mathrm{T}$ administration, there were no significant changes in germ cell populations as grouped in the categories shown in Table 1. After 14 and 20 weeks of $\mathrm{T}$ administration, significant decreases were seen in all germ cell populations from B spermatogonia through to steps 13-14 elongated spermatids. The number of A spermatogonia (Ad + Ap spermatogonia) was 
TABLE 1. Effect of $T$ implants on germ cell populations (in numbers per Sertoli cell), sperm counts, and hormone parameters in monkeys



Repeated-measures ANOVA, followed by Dunnett's test for comparison to the control group. Data is shown from the control phase, at 2, 14, and 20 weeks of $\mathrm{T}$ administration, and 12 weeks after the removal of implants (recovery). All data is mean \pm SEM. The number of animals ( $\mathrm{n}$ ) included in each time point is indicated.

${ }^{a} P<0.05$, compared with control.

${ }^{b} P<0.01$, compared with control.
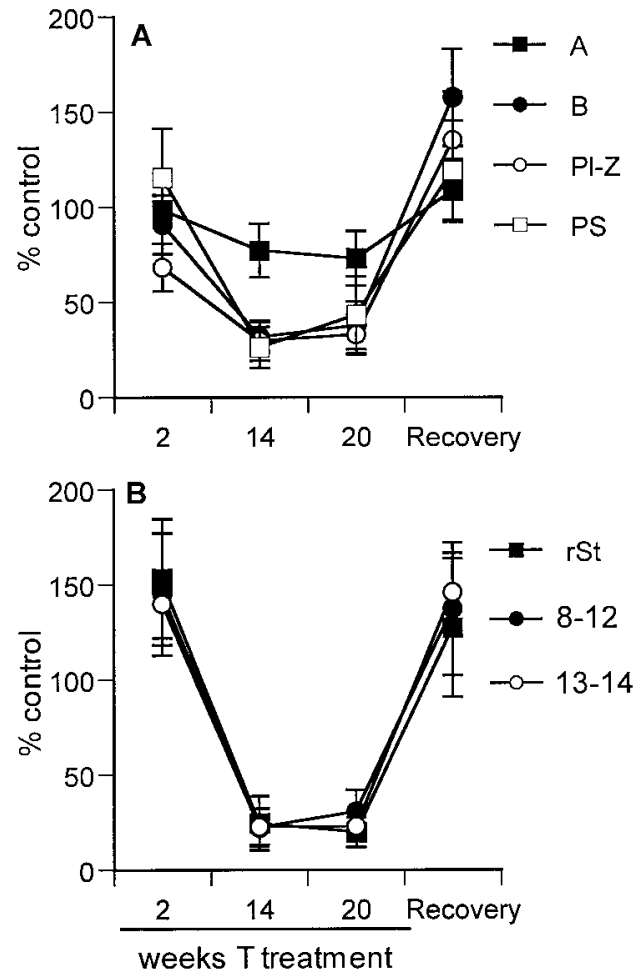

FIG. 2. Germ cell populations, expressed as percent of control after 2, 14, and 20 weeks of $\mathrm{T}$ administration, and at 12 weeks after the removal of Timplants (recovery phase). Data are expressed as mean \pm SEM $(n=9$ in all groups except 14 weeks, where $n=8)$. A, Data for spermatogonial and spermatocyte populations, type A spermatogonia $(\mathrm{A}, \mathbf{0})$, type $\mathrm{B}$ spermatogonia $(\mathrm{B}, \bullet)$, preleptotene-zygotene spermatocytes $(\mathrm{Pl}-\mathrm{Z}, \mathrm{O})$, pachytene spermatocytes (PS, $\square$ ). B, Data for spermatid populations, steps 1-7 rSt (rSt 1-7, $\mathbf{0})$, steps 8-12 elongating spermatids $(8-12, \bullet)$, steps $13-14$ elongated spermatids $(13-14, \bigcirc)$.

significantly below control only at the 20-week time point. All germ cell types recovered within 12 weeks after removal of T implants.

To appreciate the relative changes in each germ cell population during $\mathrm{T}$ administration, germ cell numbers were expressed as percent of control values (Fig. 2). The total number of type A spermatogonia remained between 73-99\% of control, across the treatment period. After 14 and 20 weeks of $\mathrm{T}$ administration, the number of type $\mathrm{B}$ spermatogonia was suppressed to $20-38 \%$ of control values. All later germ cell types were suppressed to a similar degree.

To further investigate the effects of T-induced hormonal changes on the progression of germ cell development, germ cell conversion ratios (CR) were examined after 14 and 20 weeks, when spermatogenic suppression had reached steady state. The primary defect was a significant decrease $(P<0.01)$ in the CR of A-to-B spermatogonia at the 14- and 20-week treatment time points $(C R, 0.57 \pm 0.05$ in control biopsies vs. $0.21 \pm 0.04$ after 14 weeks, and $0.25 \pm 0.06$ after 20 weeks, both $P<0.01$ ). The only other significant changes in $C R$ were seen after 20 weeks, when there was a decrease in the transition of pachytene spermatocytes through to round spermatids $(1.88 \pm 0.12$ control vs. $1.07 \pm 0.3720$ weeks, $P<0.05)$ and a decrease in the transition through the later phases of spermiogenesis, from steps 8-12 to steps 13-14 spermatids $[1.04 \pm 0.14$ control vs. $0.73 \pm 0.18$ (20 weeks), $P<0.05]$.

\section{Effect of $T$ administration on sperm counts and hormone levels}

$\mathrm{T}$ administration caused significant decreases in sperm counts, intratesticular $\mathrm{T}$ concentrations, and the levels of circulating bioactive FSH and LH (Table 1). All parameters returned to control levels within 12 weeks after the removal of T implants. All animals achieved maximal suppression of sperm counts between 10-16 weeks of treatment (Narula et al., submitted).

\section{Effect of $T$ administration on spermatogonial subtypes}

In the monkey, the type A spermatogonia population is comprised broadly of two morphologically distinct classes of spermatogonia. Ad spermatogonia (see Fig. 1) are considered to be the nonproliferative reserve spermatogonial population $(21,22,24)$, whereas the Ap spermatogonia (see Fig. 1) are considered to provide the differentiating cells committed to spermatogenesis $(21,22,24,25)$. The effects of $\mathrm{T}$ adminis- 
FIG. 3. Spermatogonial populations, expressed as number per Sertoli cell, across the study period. Data are shown for control (C), 2, 14, and 20 weeks during $\mathrm{T}$ administration; and recovery, 12 weeks after removal of T implants $(\mathrm{R})$. The data are expressed as mean $\pm \operatorname{SEM}(\mathrm{n}=9$ in all groups except 14 weeks, where $n=8$ ), and different letters denote significant differences $(P<0.05)$ in a given cell population, across the study period. Data were log-transformed before repeatedmeasures ANOVA, followed by NewmanKeuls post hoc comparison.

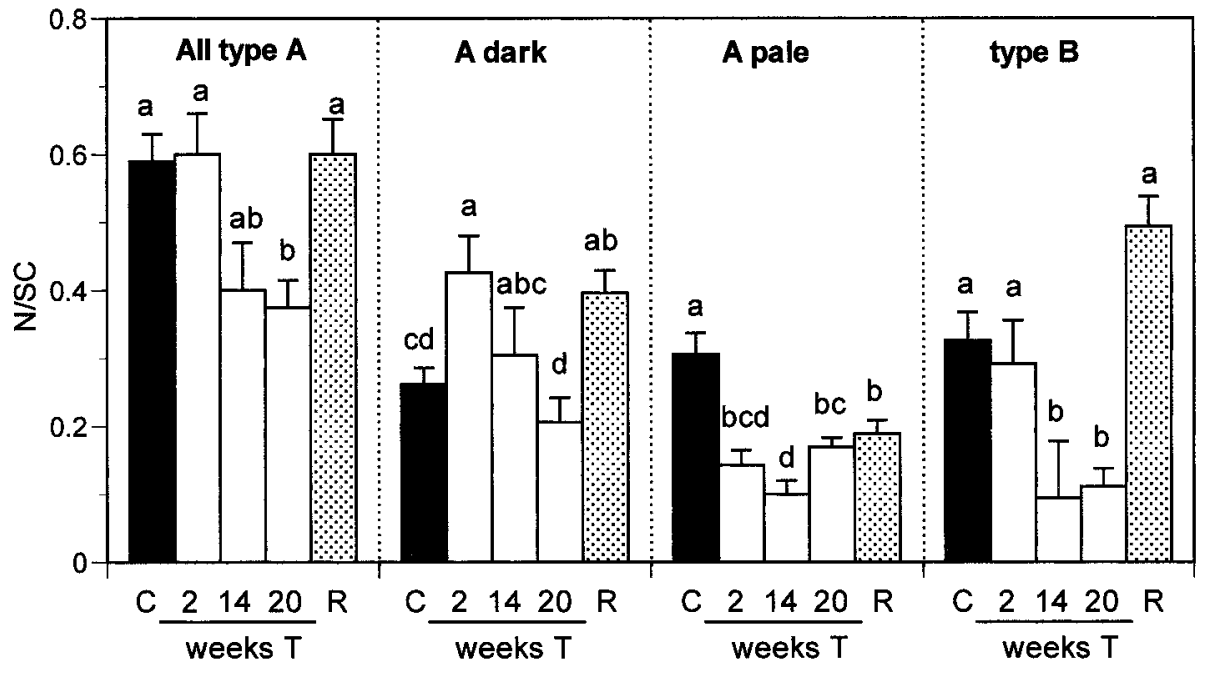

tration on type Ad, Ap, and B spermatogonia were considered (Fig. 3).

After 2 weeks of $\mathrm{T}$ administration, whereas the total number of type A spermatogonia (i.e. Ad + Ap spermatogonia) was unaltered (Table 1, Fig. 3), changes were seen when the type A spermatogonial subtypes were considered separately. As shown in Fig. 3, type Ap spermatogonia were suppressed to $45 \%$ of control $(P<0.05)$, and Ad spermatogonia increased to $165 \%$ of control $(P<0.05)$. Despite these changes, no change was seen in $B$ spermatogonia at this time.

After 14 weeks of $\mathrm{T}$ administration, Ap spermatogonia remained suppressed, whereas Ad spermatogonia had declined to control levels (Fig. 3). Type B spermatogonia were now suppressed to an extent similar to that of the Ap spermatogonia $(38 \%$ and $32 \%$ of control for Ap and B, respectively). After 20 weeks of $\mathrm{T}$ administration, the number of Ap spermatogonia had risen slightly, whereas the number of Ad spermatogonia decreased further (compared with 14 weeks). When the total A spermatogonial number was considered, there was a significant decrease at 20 weeks. Type B spermatogonia remained suppressed after 20 weeks of T administration. When the CR between the spermatogonial subtypes were analyzed, the only significant decrease was seen in the transition of Ap to B spermatogonia after 20 weeks (not shown).

Twelve weeks after removal of the $\mathrm{T}$ implants, the total number of A spermatogonia returned to control values (Fig. 3). Ad spermatogonia were significantly elevated above control, whereas Ap spermatogonia were significantly below control values.

\section{Failure of spermiation during $T$ administration}

There was a significant linear relationship between sperm count and the number of steps 13-14 elongated spermatids per Sertoli cell, after both $14(\mathrm{r}=0.93, P<0.001, \mathrm{n}=8)$ and 20 weeks ( $\mathrm{r}=0.81, P<0.01, \mathrm{n}=9$ ) of $\mathrm{T}$ administration. However, in some animals, the sperm count did not reflect the number of mature spermatids (steps 13-14) in the testis. For example, animal no. 97114 was azoospermic at 18 and 20 weeks but had 35\% the control number of steps 13-14 elongated spermatids in the testis, suggesting a failure of sper- miation. Therefore, the failure of spermiation was assessed during $\mathrm{T}$ administration. Because three animals had severe spermatogenic suppression after long-term $\mathrm{T}$ administration, and no elongating or elongated spermatids were present in their testes, these animals were excluded from the analysis of spermiation.

In control testicular biopsies, few mature retained spermatids were seen in the basal portion of the epithelium $(0.023 \pm 0.016 \mathrm{~N} / \mathrm{SC}, \mathrm{n}=6)$, and similar numbers were seen after 2 weeks of $\mathrm{T}$ administration $(0.046 \pm 0.016, \mathrm{n}=6)$. After 14 and 20 weeks of $T$ administration, the numbers of retained spermatids per Sertoli cell increased to $0.071 \pm 0.018(n=5)$ and $0.235 \pm 0.179(n=6)$, respectively; however, there was marked between-animal variability. To make an estimate of the degree of spermiation failure, the number of spermatids retained in the epithelium was compared with the number of spermatids available to spermiate (Table 2). Animals that had higher sperm counts had less retained spermatids and a lower percentage of spermatids retained (Table 2). A significant negative correlation was seen between sperm count and the percentage of spermatids retained after $14(\mathrm{r}=-0.83$, $\mathrm{n}=5, P<0.02)$ and 20 weeks $(\mathrm{r}=-0.94, \mathrm{n}=6, P<0.001)$.

\section{Heterogeneity of response to $T$ administration}

Animals showed heterogeneous suppression of sperm counts, with some animals achieving consistent azoospermia, whereas others achieved variable degrees of spermatogenic suppression (17). As described elsewhere (17; and Narula et al., submitted), animals were assigned into two groups: those showing sustained azoospermia up to 20 weeks of $\mathrm{T}$ administration (azoo group, $\mathrm{n}=4$ ), and those that did not show consistent suppression, with consistently detectable sperm counts ranging between 1 and $40 \%$ of their control values (nonazoo group, $\mathrm{n}=5$ ).

Figure 4 shows germ cell development (N/SC expressed as a percent of control) at 14 weeks of $\mathrm{T}$ administration in the azoo and nonazoo groups. There was a general trend for germ cell numbers to be lower in the azoo, compared with the nonazoo group, from B spermatogonia onwards. When the data were expressed as percent of control, significant decreases in the azoo group were seen in pachytene sper- 
TABLE 2. Spermatid retention in the seminiferous epithelium, compared with sperm counts, after 14 and 20 weeks of T administration

\begin{tabular}{|c|c|c|c|c|c|c|c|c|}
\hline \multirow[b]{2}{*}{$\underset{\mathrm{ID}^{a}}{\operatorname{Animal}}$} & \multicolumn{4}{|c|}{14 weeks $\mathrm{T}$ administration } & \multicolumn{4}{|c|}{20 weeks $\mathrm{T}$ administration } \\
\hline & $\begin{array}{c}\text { Steps } 13-14 \\
\text { spermatids } \\
\text { N/SC }^{b}\end{array}$ & $\begin{array}{c}\text { Retained } \\
\text { spermatids } \\
\text { N/SC }^{c}\end{array}$ & $\begin{array}{c}\% \\
\text { Spermatids } \\
\text { retained }^{d}\end{array}$ & $\begin{array}{l}\text { Sperm } \\
\text { count }^{e}\end{array}$ & $\begin{array}{c}\text { Steps } 13-14 \\
\text { spermatids } \\
\text { N/SC }\end{array}$ & $\begin{array}{c}\text { Retained } \\
\text { spermatids } \\
\text { N/SC }\end{array}$ & $\begin{array}{c}\% \\
\text { Spermatids } \\
\text { retained }\end{array}$ & $\begin{array}{c}\text { Sperm } \\
\text { count }\end{array}$ \\
\hline 94029 & 7.20 & 0.058 & 0.68 & 19.0 & 6.48 & 0.009 & 0.12 & 51.1 \\
\hline 94028 & 3.43 & 0.030 & 0.74 & 30.8 & 3.39 & 0.042 & 1.06 & 32.4 \\
\hline 97105 & 3.59 & 0.121 & 2.89 & 23.6 & 1.17 & 0.017 & 1.22 & 13.2 \\
\hline 86185 & 1.56 & 0.103 & 5.67 & 0.1 & 1.79 & 0.075 & 3.60 & 1.5 \\
\hline 93042 & na & na & na & na & 2.71 & 0.144 & 4.55 & 0.1 \\
\hline 97114 & 0.70 & 0.041 & 5.02 & 0.1 & 0.96 & 1.126 & 100 & 0 \\
\hline
\end{tabular}

na, Biopsy not available. Data from individual animals is shown.

${ }^{a}$ Animals that did not have any elongated spermatids present in the testis were not included in the analysis $(\mathrm{n}=3)$.

${ }^{b}$ The number per Sertoli cell of steps 13-14 elongated spermatids.

${ }^{c}$ The number per Sertoli cell of step 14 elongated spermatids retained in the basal portion of the epithelium in stages VII-XII.

${ }^{d}$ Calculated by dividing the N/SC of retained spermatids by the N/SC of steps 13-14 spermatids, correcting for the different stage durations in which they are present.

${ }^{e}$ Millions per ejaculate.

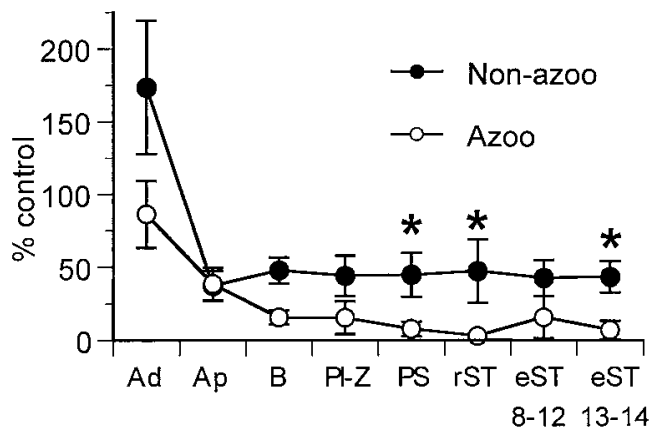

Fig. 4. Germ cell populations, expressed as percent control, after 14 weeks of $\mathrm{T}$ administration, in animals achieving consistent azoospermia (azoo; open circles), compared with those animals that did not (nonazoo; closed circles). Germ cell development from type A spermatogonia through to mature elongated spermatids is shown along the $\mathrm{x}$-axis, and the data are mean \pm SEM $(\mathrm{n}=4$ per group). *, Significant difference $(P<0.05)$ between azoo vs. nonazoo group, using Student's $t$ test. Germ cell abbreviations are as follows: Ad, A dark spermatogonia; Ap, a pale spermatogonia; B, type B spermatogonia; $\mathrm{Pl}-\mathrm{Z}$, preleptotene-zygotene spermatocytes; PS, pachytene spermatocytes; rSt $1-7$, steps $1-7$ round spermatids; eSt $8-12$, steps $8-12$ elongating spermatids; eSt 13-14, steps 13-14 elongated spermatids.

matocytes, round spermatids, and steps 13-14 elongated spermatids. When the data were expressed as N/SC, germ cell numbers were significantly lower in the azoo, compared with the nonazoo, group in all germ cell groupings except for Ap spermatogonia (not shown). There were no significant differences in the numbers of germ cells between azoo and nonazoo groups before $\mathrm{T}$ administration (not shown).

Figure 5 shows the changes in the spermatogonial subtypes in the azoo vs. nonazoo groups after 14 weeks of $\mathrm{T}$ administration. Animals in the azoo group had significantly less Ad and B spermatogonia per Sertoli cell but similar numbers of Ap. After 20 weeks, a similar pattern was observed, except that there was no difference in the number of Ad spermatogonia between the two groups (not shown).

When the CR of germ cells were considered, to assess the efficiency of the transition of germ cells through each developmental step, there was a significant decrease in the transition of Ap to B spermatogonia in the azoo (vs. nonazoo) group at both 14 weeks $(0.46 \pm 0.10$ azoo vs. $1.27 \pm 0.05$ nonazoo, $P<0.05)$ and 20 weeks $(0.23 \pm 0.06$ azoo vs. $0.82 \pm$

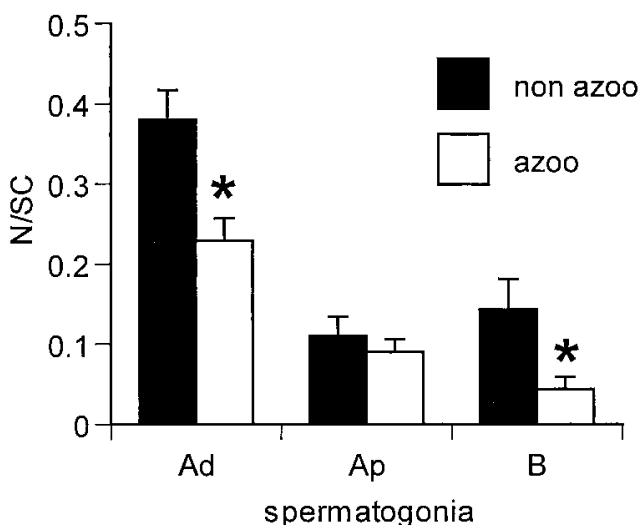

FIG. 5. Spermatogonial populations, expressed as number per Sertoli cell in azoo (open bars) vs. nonazoo (closed bars) animals after 14 weeks of $\mathrm{T}$ administration. Data are shown as mean $\pm \operatorname{SEM}(\mathrm{n}=$ 4/group). *, Significant difference $(P<0.05)$ between the azoo vs. nonazoo group, as determined by Mann-Whitney $U$ test.

0.21 nonazoo, $P<0.05$ ) of $\mathrm{T}$ administration, but there were no differences in any other germ cell CR.

Although there was no difference in the levels of FSH between the azoo and nonazoo groups during the control phase, animals in the azoo group had significantly lower immuno-FSH and bioFSH across the 20-week T-administration phase, as detailed elsewhere (17; and Narula et al., submitted). After 14 weeks of $\mathrm{T}$ administration, bioFSH was $8 \%$ of control in the azoo group vs. $77 \%$ of control in the nonazoo group $(P<0.05)$. Similarly, after 20 weeks, bioFSH was $22 \%$ of control in the azoo group vs. $65 \%$ of control in the nonazoo group $(P<0.05)$. No differences were seen between the azoo $v s$. nonazoo groups, during the treatment period, in any other endocrine parameter, including serum $\mathrm{T}$, bioLH, and intratesticular androgens (17; and Narula et al., submitted).

\section{Discussion}

In this study, we have used stereological techniques to measure the changes in germ cell development in adult macaque monkeys administered exogenous T for 20 weeks. This animal provides an excellent model for the study of human hormonal contraception, showing profound suppression of serum gonadotropin levels, but variable patterns of sper- 
matogenic suppression, in response to steroid treatment (17; Narula et al., submitted). We show that the primary lesion in all animals relates to type Ap spermatogonial development. Moreover, in animals achieving consistent azoospermia, compared with animals with variable spermatogenic suppression, the key germ cell determinant of the response of sperm counts seemed to be the more profound suppression of the conversion of type Ap to B spermatogonia, which was related to a more profound suppression of circulating FSH. We also show that during $\mathrm{T}$ administration, other sites in spermatogenesis are affected, including spermatocytes, spermatids, and the spermiation process.

The arrest of spermatogenesis at the level of type A spermatogonia, in response to gonadotropin withdrawal, is supported by other studies in monkeys, after $\mathrm{GnRH}$ antagonist administration (9-11) and hypophysectomy (8), and in humans given weekly injections of $\mathrm{T}$ enanthate (15). In the current study, we showed that, whereas total A spermatogonial numbers were unchanged after 2 weeks of T administration, a decline in Ap spermatogonial number was apparent; and thus, Ap spermatogonia were the first germ cell type to show a significant decrease after gonadotropin withdrawal. In all animals, a major reduction in Ap spermatogonial number was seen at 14 and 20 weeks of T administration, and CR data showed that the progression of germ cells through the pachytene spermatocyte stage and spermiogenesis was also impaired, albeit to a lesser extent. We speculate that losses of pachytene spermatocytes and spermatids result from apoptosis, as has been previously described in gonadotropin-deprived rats $(26,27)$.

We recently reported that monkeys achieving consistent azoospermia had significantly lower levels of circulating FSH (both immuno- and bioactive FSH) (17; Narula et al., submitted), whereas no differences were seen in serum bioLH and T, or testicular androgen levels. These data suggest that residual FSH plays a key role in supporting spermatogenesis during $\mathrm{T}$-induced gonadotropin suppression. The heterogenous sperm count response seen in these monkeys also allowed us to compare germ cell numbers, sperm counts, and FSH levels in animals achieving either consistent azoospermia or variable spermatogenic suppression. The 14week time point during $\mathrm{T}$ administration was investigated to understand changes in the spermatogenic process that would promote subsequent changes in sperm output during the remaining 6 weeks of the T-administration phase. Analysis of the germ cell data at 14 weeks showed that, whereas Ap spermatogonia were similarly suppressed in both the azoo and nonazoo groups, all other germ cell types were lower in the azoospermic animals. Analysis of CR between germ cell types showed that the reduction in the transition of Ap to B spermatogonia was a major subsequent determinant of sperm output. Therefore, induction of consistent azoospermia is associated with lower circulating FSH levels (17; and Narula et al., submitted), a greater impairment of either B spermatogonial survival or in the transition of Ap to $B$ spermatogonia, leading to fewer germ cells being available to proceed through spermatogenesis.

Type A spermatogonia in the primate and the human can be divided into at least two morphologically distinct subtypes: Ad and Ap (22). Type Ap spermatogonia divide in the later stages of the spermatogenic cycle, to produce type B spermatogonia, as well as to renew their own population (21, $22,24,25,28,29)$. Ad spermatogonia, however, rarely divide and are thus considered to be resting or reserve stem cells (21, $22,24,25,28,29)$. Ap spermatogonia have been suggested to be the true stem cells of the testis, because Ap (and not Ad) spermatogonia are seen in humans after radiation therapy (30), after long-term estrogen therapy, and in the postpubertal cryptorchid testes (31). Thus, Ap spermatogonia are probably the stem cells of the testis that renew their own population as well as produce cells committed to differentiation. Various studies have suggested that Ap spermatogonia can undergo a transition, probably without division, into Ad spermatogonia $(24,28,29)$. Because Ad spermatogonia are not proliferative, the transition of Ap into Ad may be a means of inactivating a certain proportion of the spermatogonial population $(28,29)$. Moreover, studies in irradiated monkeys suggest that Ad spermatogonia may be able to undergo a transition back to Ap spermatogonia, thus allowing repopulation of the testis $(28,29)$, further suggesting that Ad spermatogonia are reserve stem cells.

$\mathrm{T}$ implants caused a decrease in Ap spermatogonia within 2 weeks, and this decrease in Ap spermatogonia eventually led to subsequent decreases in germ cells from type B spermatogonia onwards. Other investigators have shown reductions in Ap spermatogonia after long-term gonadotropin suppression (9) or hypophysectomy (8) in macaques. This reduction may involve the inhibition of the mitosis of Ap spermatogonia, because GnRH antagonist treatment of macaque monkeys decreased Ap spermatogonia in the stages in which mitosis occurs (11), and this led to a disappearance of proliferating cell nuclear antigen-labeled Ap spermatogonia from the testis (25). The relative role of androgens and FSH in this loss of Ap spermatogonia is unclear. FSH treatment stimulated Ap spermatogonial number in either GnRH antagonist-treated (9) or normal (12) macaques; however, their number can also be maintained by androgens (8), suggesting a role for each hormone. In the current study, Ap spermatogonia were maximally suppressed within 2 weeks, at a time when there were more substantial reductions in testicular $\mathrm{T}$ than in serum FSH. Our study paradigm does not allow us to identify the relative contributions of the suppression of $\mathrm{T}$ and FSH to the impairment of Ap spermatogonial number. Clearly, the fall in intratesticular $\mathrm{T}$ levels could have contributed to the reduction in Ap spermatogonia; however, we cannot exclude the possibility that the reduction in serum $\mathrm{FSH}$ bioactivity is the major regulator of this impairment.

Species differences between primates in the regulation of spermatogonial number may exist. In rhesus monkeys, B spermatogonia, rather than Ap spermatogonia, seem to be hormone-sensitive, because only B spermatogonial numbers increased after administration of FSH to hypophysectomized animals (13). Also, unilaterally orchidectomized rhesus monkeys, which had significant increases in circulating FSH levels, showed increases in B spermatogonia but not Ap populations (14). However, although a change in Ap numbers was not seen, it is possible that the mitotic activity of Ap spermatogonia may still be stimulated by FSH in these monkeys, leading to the increased numbers of B spermatogonia. In juvenile rhesus monkeys, FSH alone (32), or both FSH and 
$\mathrm{T}$ (33), stimulated Ap spermatogonial number, suggesting that, in young rhesus monkeys, these cells are hormonally responsive.

The lower circulating FSH levels in azoospermic animals were associated with a significant decrease in the conversion of Ap to B spermatogonia, leading to a lower number of B spermatogonia per Sertoli cell. Thus, in the azoospermic animals, B spermatogonia may have had a decreased mitotic activity and/or undergone apoptosis, because of lower levels of FSH. As the number of Ap spermatogonia were similarly reduced in both azoo and nonazoo groups, we speculate that Ap spermatogonia are maintained at a higher level of FSH than are type B spermatogonia. An alternative explanation is that the lower FSH levels in the azoospermic animals cause a further reduction in the mitotic activity of Ap spermatogonia during their differentiation into type B spermatogonia, leading to few B spermatogonia being produced. Therefore, all of the effects of FSH suppression may be at the level of Ap spermatogonia rather than $\mathrm{B}$. A third explanation for the data is that Ap spermatogonia may be regulated by FSH and/or $\mathrm{T}(8,9,12)$, whereas $\mathrm{B}$ spermatogonia may be primarily regulated by $\mathrm{FSH}$, as has been postulated (13).

The suggestion that Ap and B spermatogonia may be differentially regulated may explain the discrepancy between our current and previous studies (11). Though the current study shows that 2 weeks of $\mathrm{T}$ administration caused a decrease in Ap spermatogonia (yet no change in type B), previous studies in monkeys given a GnRH antagonist for 16 or 25 days demonstrated decreases in B spermatogonia in the absence of significant changes in Ap spermatogonia (11). Although that study showed Ap spermatogonial mitosis was impaired, as evidenced by a decrease in the proportion of Ap spermatogonia in stages VII-XII, wherein Ap spermatogonial mitosis occurs, the primary defect was in type B spermatogonia (11). FSH levels were not measured in the GnRH antagonist-treated animals (11), but it is possible that GnRH antagonist treatment caused a more rapid suppression of circulating FSH than $\mathrm{T}$ administration, leading to more marked and rapid effects on B spermatogonia.

The increase in Ad spermatogonia after 2 weeks of $\mathrm{T}$ administration, and a second increase after removal of the T implants, was unexpected. It is believed that Ad spermatogonia do not proliferate $(22,25)$, and thus they are unlikely to proliferate in response to $\mathrm{T}$ administration. We suggest that Ap spermatogonia cease to proliferate after gonadotrophin withdrawal, as has been demonstrated (25), and instead undergo a transition into resting $\mathrm{Ad}$ spermatogonia. Ap spermatogonia have been suggested to form Ad spermatogonia in normal monkeys via transitional type A (At) spermatogonia (24). In our study, At spermatogonia were classified as Ad spermatogonia. Studies in irradiated monkeys suggest that Ap are inactivated into Ad spermatogonia soon after irradiation (28, 29). Thus, it is possible that gonadotropins stimulate Ap proliferation, whereas gonadotropin suppression causes a transition into nonproliferative Ad forms. Studies in rhesus monkeys have shown decreases in Ad spermatogonia after either administration of FSH to juvenile monkeys (34) or a unilateral-orchidectomy-induced rise in FSH (14). Thus, Ad spermatogonia are increased during gonadotro- pin suppression, when there is a decrease in more differentiated spermatogonial subtypes (current study), yet are decreased during FSH stimulation, when more differentiated spermatogonia are present and proliferating (14, 34). The subsequent decline in Ad spermatogonia after 14 and 20 weeks of $\mathrm{T}$ administration in the current study may have been attributable to further losses of Ap spermatogonia or a decrease in the rate of transition into Ad forms. At 12 weeks of recovery, Ad spermatogonia were increased, and Ap spermatogonia decreased, yet the total population of A spermatogonia was normal. This data suggests that altered spermatogonial dynamics persist for at least 2 spermatogenic cycles.

The failure of spermiation was apparent after long-term $\mathrm{T}$ administration. There were few retained spermatids in biopsies taken after 2 weeks of treatment, and no significant reduction in sperm counts, suggesting that significant spermiation failure did not occur within 2 weeks. Although considerable spermiation failure was seen after 1 week of FSH and $\mathrm{T}$ suppression in rats, the experimental design ensured a rapid suppression of gonadotropin and T levels (16). In monkeys, spermatid retention has been noted after 16 and 25 days of GnRH antagonist treatment (11) and may be attributable to a more rapid suppression of gonadotropins with this treatment. Also, trials in humans, using T in combination with cyproterone acetate to promote the rapid suppression of gonadotropins, leads to a marked suppression of sperm counts within 4 weeks (3), suggesting early defects in spermiation. In the current study, spermiation failure was present, to a variable extent, after 14 and 20 weeks of T administration. Spermiation failure was particularly evident in animals with severe spermatogenic suppression, i.e. sperm counts less than 3 million per ejaculate. For example, one animal (no. 86185) had sperm counts which ranged from 0.1-1.5 million per ejaculate, germ cell numbers approximately $40 \%$ of control, and high numbers of retained spermatids, compared with animals with less severe suppression of sperm counts. Another animal (no. 97114) that was azoospermic between weeks 16-20 continued to show germ cell numbers at approximately $35 \%$ of control and had high numbers of retained spermatids. The demonstration of a negative correlation between sperm counts and retained spermatids suggests that spermiation failure contributes to a more severe suppression of sperm counts. The reason for spermiation failure in individual monkeys in the current study was not immediately obvious from their serum hormone data. Other studies involving long-term suppression of gonadotropins in monkeys have noted an accumulation of elongated spermatids in the testis, indicating spermiation failure (35). Our recent study in men receiving long-term T enanthate treatment also showed that some men who became azoospermic had elongated spermatids present in their biopsies, indicating that spermiation failure is a feature of long-term $\mathrm{T}$ administration in humans (15). Spermiation failure is seen after FSH and/or T suppression in rats (16) and is often noted in other situations, such as after the administration of reproductive toxicants (see Ref. 36 for review). The mechanism of spermiation failure is unknown but is presumably mediated by the Sertoli cell, because this cell contains the hormone receptors, and the elongated sperma- 
tids have ceased to be transcriptionally active. Immunocytochemical studies in rats have suggested that spermatids that fail to spermiate retain adhesion molecules on their surface, suggesting that a defect in the removal of adhesion molecules may be involved (37).

In summary, this study has described the effects of Tinduced gonadotropin suppression on germ cell populations in adult macaques. Gonadotropin suppression caused a primary defect in Ap spermatogonia that leads to subsequent decreases in other germ cells. Cells were also lost during the pachytene spermatocyte and spermatid phases, probably via apoptosis. Spermiation failure was demonstrated in animals with marked suppression of sperm counts, yet maintenance of elongated spermatid production in the testis. Animals that had low circulating FSH with an induction of consistent azoospermia (17; and Narula et al., submitted) had a significant defect in the transition of Ap to B spermatogonia, suggesting an important role for FSH in the maintenance of B spermatogonia. The data suggests that, although defects in Ap spermatogonial development is a primary defect in monkey spermatogenesis, the basis for the variable suppression of sperm counts in T-treated monkeys is attributable to a more profound suppression of the transition between Ap and B spermatogonia, as well as defects in spermiation.

\section{References}

1. World Health Organization Task. 1990 Force on methods for the regulation of male fertility. Contraceptive efficacy of testosterone-induced azoospermia in normal men. Lancet. 336:955-959.

2. Martin CW, Riley SC, Everington D, et al. 2000 Dose-finding study of oral desogestrel with testosterone pellets for suppression of the pituitary-testicular axis in normal men. Hum Reprod. 15:1515-1524.

3. Meriggiola MC, Bremner WJ, Paulsen CA, et al. 1996 A combined regimen of cyproterone acetate and testosterone enanthate as a potentially highly effective male contraceptive. J Clin Endocrinol Metab. 81:3018-3023.

4. World Health Organization Task. 1996 Force on methods for the regulation of male fertility. Contraceptive efficacy of testosterone-induced azoospermia and oligozoospermia in normal men. Fertil Steril. 65:821-829.

5. McLachlan RI, Wreford NG, O'Donnell L, de Kretser DM, Robertson DM. 1996 The endocrine regulation of spermatogenesis: independent roles for testosterone and FSH. J Endocrinol. 148:1-9.

6. Sharpe RM. 1994 Regulation of spermatogenesis. In: Knobil E, Neill J D, eds. The physiology of reproduction. 2nd ed. New York: Raven Press Ltd.; 1363-1434.

7. Weinbauer GF, Nieschlag E. 1993 Hormonal control of spermatogenesis. In: de Kretser DM, ed. Molecular biology of the male reproductive system. San Diego: Academic Press; 99-142.

8. Marshall GR, Jockenhovel F, Ludecke D, Nieschlag E. 1986 Maintenance of complete but quantitatively reduced spermatogenesis in hypophysectomized monkeys by testosterone alone. Acta Endocrinol (Copenh). 113:424-431.

9. Weinbauer GF, Behre HM, Fingscheidt U, Nieschlag E. 1991 Human folliclestimulating hormone exerts a stimulatory effect on spermatogenesis, testicular size, and serum inhibin levels in the gonadotropin-releasing hormone antagonist-treated nonhuman primate (Macaca fascicularis). Endocrinology. 129:1831-1839.

10. Weinbauer GF, Gockeler E, Nieschlag E. 1988 Testosterone prevents complete suppression of spermatogenesis in the gonadotropin-releasing hormone antagonist-treated nonhuman primate (Macaca fascicularis). J Clin Endocrinol Metab. 67:284-290

11. Zhengwei Y, Wreford NG, Schlatt S, Weinbauer GF, Nieschlag E, McLachlan RI. 1998 Acute and specific impairment of spermatogonial development by $\mathrm{GnRH}$ antagonist-induced gonadotrophin withdrawal in the adult macaque (Macaca fascicularis). J Reprod Fertil. 112:139-147.

12. van Alphen MM, van de Kant HJ, de Rooij DG. 1988 Follicle-stimulating hormone stimulates spermatogenesis in the adult monkey. Endocrinology. 123:1449-1455.

13. Marshall GR, Zorub DS, Plant TM. 1995 Follicle-stimulating hormone amplifies the population of differentiated spermatogonia in the hypophysectomized testosterone-replaced adult rhesus monkey (Macaca mulatta). Endocrinology. 136:3504-3511.

14. Ramaswamy S, Marshall GR, McNeilly AS, Plant TM. 2000 Dynamics of the follicle-stimulating hormone (FSH)-inhibin B feedback loop and its role in regulating spermatogenesis in the adult male rhesus monkey (Macaca mulatta) as revealed by unilateral orchidectomy. Endocrinology. 141:18-27.

15. Zhengwei Y, Wreford NG, Royce P, de Kretser DM, McLachlan RI. 1998 Stereological evaluation of human spermatogenesis after suppression by testosterone treatment: heterogeneous pattern of spermatogenic impairment. J Clin Endocrinol Metab. 83:1284-1291.

16. Saito K, O'Donnell L, McLachlan R, Robertson D. 2000 Spermiation failure is a major contributor to early spermatogenic suppression caused by hormone withdrawal in adult rats. Endocrinology. 141:2779-2785.

17. Narula A, O'Donnell L, Yi-Oun G, et al., A possible key role for FSH in maintaining spermatogenesis in monkeys. Proc of the 82nd Meeting of The Endocrine Society, Toronto, Canada, 2000, p 336.

18. Endocrine Society. 1997 Guidelines for the care and use of experimental animals. J Clin Endocrinol Metab. 82:40.A.

19. O'Donnell L, Stanton PG, Wreford NG, Robertson DM, McLachlan RI. 1996 Inhibition of $5 \alpha$-reductase activity impairs the testosterone-dependent restoration of spermiogenesis in adult rats. Endocrinology. 137:2703-2710.

20. Zhengwei Y, McLachlan RI, Bremner WJ, Wreford NG. 1997 Quantitative (stereological) study of the normal spermatogenesis in the adult monkey (Macaca fascicularis). J Androl. 18:681-687.

21. Clermont Y. 1969 Two classes of spermatogonial stem cells in the monkey (Cercopithecus aethiops). Am J Anat. 126:57-71.

22. Clermont Y. 1972 Kinetics of spermatogenesis in mammals: seminiferous epithelium cycle and spermatogonial renewal. Physiol Rev. 52:198-236.

23. Wreford NG. 1995 Theory and practice of stereological techniques applied to the estimation of cell number and nuclear volume in the testis. Microsc Res Tech. 32:423-436.

24. Fouquet JP, Dadoune JP. 1986 Renewal of spermatogonia in the monkey (Macaca fascicularis). Biol Reprod. 35:199-207.

25. Schlatt S, Weinbauer GF. 1994 Immunohistochemical localization of proliferating cell nuclear antigen as a tool to study cell proliferation in rodent and primate testes. Int J Androl. 17:214-222.

26. Hikim AP, Wang C, Leung A, Swerdloff RS. 1995 Involvement of apoptosis in the induction of germ cell degeneration in adult rats after gonadotropinreleasing hormone antagonist treatment. Endocrinology. 136:2770-2775.

27. Brinkworth MH, Weinbauer GF, Schlatt S, Nieschlag E. 1995 Identification of male germ cells undergoing apoptosis in adult rats. J Reprod Fertil. 105:25-33.

28. van Alphen MM, van de Kant HJ, de Rooij DG. 1988 Depletion of the spermatogonia from the seminiferous epithelium of the rhesus monkey after X irradiation. Radiat Res. 113:473-486.

29. van Alphen MM, van de Kant HJ, de Rooij DG. 1988 Repopulation of the seminiferous epithelium of the rhesus monkey after X irradiation. Radiat Res. 113:487-500

30. Schulze C. 1979 Morphological characteristics of the spermatogonial stem cells in man. Cell Tissue Res. 198:191-199.

31. Schulze C. 1981 Survival of human spermatogonial stem cells in various clinical conditions. Fortschr Der Androl. 7:58-68.

32. Schlatt S, Arslan M, Weinbauer GF, Behre HM, Nieschlag E. 1995 Endocrine control of testicular somatic and premeiotic germ cell development in the immature testis of the primate Macaca mulatta. Eur J Endocrinol. 133:235-247.

33. Arslan M, Weinbauer GF, Schlatt S, Shahab M, Nieschlag E. 1993 FSH and testosterone, alone or in combination, initiate testicular growth and increase the number of spermatogonia and Sertoli cells in a juvenile non-human primate (Macaca mulatta). J Endocrinol. 136:235-243.

34. Ramaswamy S, Plant TM, Marshall GR. 2000 Pulsatile stimulation with recombinant single chain human luteinizing hormone elicits precocious Sertoli cell proliferation in the juvenile male rhesus monkey (Macaca mulatta). Biol Reprod. 63:82-88

35. Aravindan GR, Gopalakrishnan K, Ravindranath N, Moudgal NR, 1993 Effect of altering endogenous gonadotrophin concentrations on the kinetics of testicular germ cell turnover in the bonnet monkey (Macaca radiata). J Endocrinol. 137:485-495.

36. Russell LD. 1991 The perils of sperm release- 'let my children go'. Int J Androl. 14:307-311.

37. Wine RN, Chapin RE. 1999 Adhesion and signaling proteins spatiotemporally associated with spermiation in the rat. J Androl. 20:198-213. 